\title{
A Conceptual Design of an Integrated Façade System to Reduce Embodied Energy in Residential Buildings
}

\author{
Wen Pan ${ }^{1, *}$, Kepa Iturralde ${ }^{1}$, Thomas Bock ${ }^{1} \oplus$, Roberto Garay Martinez ${ }^{2}{ }^{\oplus}$, Olga Macias Juez ${ }^{2}$ \\ and Pietro Finocchiaro ${ }^{3}$ \\ 1 Department of Architecture, Technical University of Munich, 80333 Munich, Germany; \\ kepa.iturralde@br2.ar.tum.de (K.I.); thomas.bock@br2.ar.tum.de (T.B.) \\ 2 TECNALIA, Basque Research and Technology Alliance (BRTA), Bizkaia Science and Technology Park, \\ Building 700, 48160 Derio, Spain; roberto.garay@tecnalia.com (R.G.M.); olga.macias@tecnalia.com (O.M.J.) \\ 3 SolarInvent srl, 95030 Catania, Italy; pietro.finocchiaro@solarinvent.com \\ * Correspondence: wen.pan@br2.ar.tum.de; Tel.: +49-89-2892-5591
}

Received: 25 May 2020; Accepted: 9 July 2020; Published: 16 July 2020

check for updates

\begin{abstract}
The overall energy requirement of a building may be impacted by the building design, the selection of materials, the construction methods, and lifecycle management. To achieve an optimum energy-efficiency level when dealing with a new building or renovation project, it is important to improve the entire construction process as it is not enough to merely focus on the operational phase. If conventional construction practices do not evolve, compromise, or adapt to necessary changes, then it becomes challenging to deliver an ultimate low energy building. (2) This paper demonstrates the trend of off-site prefabrication and its production principles and the notions of open-building design and Design for $X$, as well as offering an overview of the development of automation in construction, which provides both insights and evaluations based on the context of the research. (3) Three European Union Horizon 2020 research projects were evaluated, and the outcome of the projects served as the backbone for the research and inspired the design of the proposed integrated façade system. Two design scenarios were proposed to demonstrate the potential improvements that could be achieved in a new build as well as in renovation projects. (4) The research lays a foundation for establishing a larger cross-disciplinary collaboration in the future.
\end{abstract}

Keywords: integrated façade; prefabrication; energy requirement; construction automation

\section{Introduction}

The construction industry is one of the major contributors to a nation's economic growth, in which residential construction takes a huge proportion of the overall construction volume. The construction sector is also responsible for $30-40 \%$ of the world's energy use [1]. There is an increasing effort from both academia and the construction industry towards minimizing a built environment's impact on climate change and reducing global greenhouse gas (GHG) emissions. This is commonly achieved by introducing low energy building or settlement initiatives that are equipped with a renewable energy source as well as other innovative energy producing technologies. In general, buildings are being constructed with a variety of methods, yet each method and technique may offer different required amounts of energy throughout the building's lifecycle. Delivering a truly low energy building must include every step-design, production, transportation, construction, operation, renovation and maintenance, demolition, recycling or landfill-in the building's lifecycle as every single step plays an important role that could influence the required amount of energy of the building and help determine the overall energy performance of the building. Therefore, none of the aforementioned steps can be overlooked when delivering a low energy building in practice. As a low energy building designer, 
the following aspects shall be taken into consideration: selecting the appropriate building method and system according to the project brief; proposing an on-site erection method that increases productivity, affordability, and safety; considering a building as a collection of systems rather than a permanent individual piece; designing a low energy building that not only minimizes the energy required for heating and cooling but fundamentally reduces other energy use, such as embodied energy (EE), recurring embodied energy (REE), operating energy (OE), and demolition energy (DE).

The aims of this study are (1) to evaluate the benefits of adopting prefabricated construction technology for low energy building design, (2) to develop an integrated energy production system that incorporates the Freescoo system and prefabricated frame structure, (3) to investigate the scalability of the proposed system, such as the applicability of implementing the proposed system not only in new-build projects but also in renovation projects, and to explore the potential to adopt construction automation technology in system assembly and maintenance, (4) to compare the proposed system with the conventional construction method and to identify the potential EE reduction potential, and (5) to emphasize the importance of cross-disciplinary collaboration and project management while dealing with low energy building design. Finally, the study presents a cross-disciplinary approach that not only focuses on adopting innovative technologies but also looks into how to improve building energy performance from changing the way buildings are being designed, produced, erected, maintained, and decommissioned.

This research investigates several EU Horizon 2020 research projects that provide a comprehensive insight into how prefabrication, construction automation, and technology integration have the potential to enhance EE in the energy-efficient building lifecycle. The research uses the Freescoo system from the ZERO-PLUS project as an example to demonstrate the potential of integrating an innovative energy production system with a prefabricated façade element, which is inspired by the open-building (OB) concept, as well as the Building Energy Renovation Through Timber Prefabricated Modules (BERTIM) project. A semi-automated installation system is proposed to install the proposed integrated façade system, and the design concept is inspired by the Hephaestus project. The aforementioned projects are described in detail in the methodology section.

The research involves a multidisciplinary collaboration between a construction expert, construction robotics specialists, a building physicist, a mechatronic engineer, and research institutions. The proposed system in the later section has been developed only as a conceptual design to support the research inclination. A few influential construction trends and design terminologies were introduced, such as off-site prefabrication, Design for $\mathrm{X}$, automation in construction, and they were supported by case studies so that each project provided insight on how prefabricated façade elements, the integration of energy production technology, and advanced construction methods can improve the installation process as well as renovation tasks over the building lifecycle, therefore potentially improving the overall building energy requirement.

\section{Background}

When developing a low energy building, the designer needs to be aware of the amount of EE consumed in the various phases of construction, including manufacturing, transportation, construction or installation, maintenance, and demolition. The manufacturing phase consists of the energy consumed for virgin material extraction and production. The transportation phase has to take the transport method, distance, and material weight into consideration. The construction or installation phase focuses on the direct energy consumed during on-site operation, equipment usage, fuel, electricity, and labor usage. The demolition phase underlines the energy required at the end of the building's service life, such as the demolition process, transporting the construction waste to the landfill site, and recycling or reconditioning the decommissioned materials or building components [2].

Previous research indicates that unless the construction industry changes some current practices in how buildings are constructed and refurbished, it will be extremely challenging to achieve effective GHG and EE reductions. Constructing a building consumes energy in the aforementioned phases, 
either directly or indirectly, and the selection of building materials and construction methods can influence the EE, REE, OE, and DE of the building lifecycle [3]. According to relevant studies, approximately $10-20 \%$ of energy use is generated through the manufacturing of building materials and the construction phase constitutes roughly $0.4-12 \%$, depending on the specific construction methods that were adopted [4]. The largest amount of energy is consumed during the building's operational phase and is usually around $70-80 \%$ of the lifecycle energy distribution, however, current efforts in implementing renewable energy technology have brought the operational energy of many new-build projects down dramatically [5]. The energy deployed during the renovation phase is approximately $15 \%$ of the building lifecycle required amount of energy while the demolition of the building comprises about $1 \%$ of that total required energy [6]. Fortunately, the implementation of renewable energy production products can reduce a building's operational energy amount. Attention shall, therefore, be given to how to achieve a reduction in energy required in other phases of the building lifecycle [7]. According to research conducted on lifecycle energy use in various building types, it is notable that building services, such as heating, ventilation and air conditioning (HVAC) systems represent as much as $25 \%$ of REE usage during the construction and renovation phases [8]. This finding shows that because the HVAC system is often an additional component of the building structure or envelope, it is usually installed after the building is constructed. It also has a relatively short lifespan and therefore requires regular maintenance and repair to stay in operational order. Ordinarily, the building service system is installed after the building structure has been completed and is often hidden in an interior wall or ceiling, making it difficult to access when required. Usually, channels have to be chiseled out in the concrete or masonry walls to accommodate electrical wires or pipes. If the wall was constructed with wooden or steel framing, maintaining or repairing the service appliances requires removing the outer wall finishing layer, which is often comprised of gypsum plasterboard. Several studies have compared the necessary amount of energy required between conventional construction methods and prefabricated construction methods. For instance, a study investigated the GHG emissions between prefabrication and conventional building methods and the authors suggest that prefabrication methods offer significantly reduced energy usage and provide huge environmental benefits [9]. Another study shows that despite the overall improvement of the amount of required EE when adopting off-site prefabrication methods, the EE consumption during off-site material production, building part production, component production, on-site installation, and, especially, internal infill and partitions are higher than conventional construction methods by approximately $5.7 \%$. However, a building erected using a prefabrication method shows considerable OE, REE, and DE reduction over the building's lifecycle, an estimated 15\% decrease [10]. Furthermore, to make the correct decisions when carrying out a new build or retrofit, the existing building can also assist the designers in determining an optimal energy requirement for the project. The method featured in the study requires a multicriteria two-step decision-making tool that supports the designer in choosing the optimum energy retrofit plan for new-build and retrofitting projects. The two-step decision-making tool consists of the decision design phase and decision-making phase, which demonstrated an effective method for screening optimal solutions [11]. The next section will introduce the opportunities provided by off-site prefabrication methods, in particular, through a discussion on how to minimize the required energy throughout the building's lifecycle by implementing off-site prefabrication methods.

\subsection{Overview of Off-Site Prefabrication}

Off-site prefabrication is a type of manufacturing process. Off-site manufacturing (OSM), in general, is the process of transforming raw materials, components, or parts into an end product for a customer, achieved by using different kinds of resources (e.g., labor and energy). In the construction industry, the concept of manufacturing is used slightly differently from other sectors, such as the automobile industry, because there are both on-site and off-site versions. Dwellings can be erected on the building site, commonly known as on-site construction, while parts, or even whole systems, of a dwelling, can be produced and assembled at an off-site factory, away from the project, before being shipped 
on-site for final assembly, a method commonly referred to as off-site manufacturing. This is in line with the definition of OSM used as "components or complete products that are manufactured in a structured environment distant from the location where they are finally used" [12]. Off-site manufacturing can be described as a transition of major assembly and installation activities from the construction site to remote factories [13]. In the factory, building components are produced by multiple original equipment manufacturers (OEMs), using raw materials and parts. Subsequently, they are prefabricated and transported to the construction site where they are joined physically and chemically to form part of the final building. Today, new processes and technologies have the potential to improve efficiency throughout the production and assembly phases of the construction process.

The traditional construction sector is often referred to as labor-intensive, wasteful, dangerous, and inefficient [14]. In recent years, off-site prefabrication has gained popularity and due to technological advancement, this recent trend in off-site prefabrication has integrated many other advanced approaches, including automated manufacturing, robotics, modularity, and Building Information Modeling (BIM). The advantages of off-site prefabrication methods are numerous, depending on the project goals, but could include consistent quality, a minimal duration of on-site operations, punctuality, a reduction of health and safety risks, and higher accuracy in cost planning [15].

In the context of this research, the main focus is on investigating if off-site prefabrication can reduce the required amount of $\mathrm{EE}$ in some of the building's lifecycle. A study compared two case studies to analyze the GHG emissions between a conventional construction method and a semi-prefabrication method. The study showed energy reduction in construction equipment usage, building material usage, and the transportation of construction waste [16]. On the other hand, there was a noticeable energy consumption increase in the transportation of prefabricated construction parts and components. The study showed that while off-site prefabrication reduced energy usage over a conventional construction method, the operational and demolition phases of the buildings were completely overlooked. The lifecycle environmental benefits of prefabricated modular steel and timber residential buildings over a conventional concrete residential building were investigated [10]. For comparative purposes, all three buildings had similar floor space and overall spatial composition. The operational energy analysis was conducted using TRNSYS simulation software and was based on the local heating and cooling consumption and the average performance of the case study building [10]. The results showcased the difference in the total operational energy amount of the case study buildings: the steel off-site prefabricated modular building consumed the most energy, the timber frame structure consumed the median, and the conventional concrete building consumed the least. The lifecycle energy requirements of the three case study buildings with different construction methods were assessed based on the assumption there is no heating loss or improvement over a 50-year period. The study found that the steel structure contributed approximately $36 \mathrm{GJ} / \mathrm{m}^{2}$ and the conventional concrete provided $30 \mathrm{GJ} / \mathrm{m}^{2}$. The energy required for the replacement of building materials, parts, and components was assumed to be up to $32 \%$ of the initial EE and this amount is shared between off-site prefabrication and conventional methods. A study implies that the reuse of construction material can have a positive impact on the environment. The steel and timber prefabricated buildings could be disassembled with many of the structural elements to be reused for a new building, whereas the conventional structural concrete would have to be crushed and used as aggregates in new concrete production [10]. Further, the steel rebar would need to be extracted from the demolished reinforced concrete and melted down, consuming even more energy during the recycling process [16]. From a lifecycle energy performance point of view, the off-site prefabricated steel building consumes more energy than the conventional concrete building, however, up to $81.3 \%$ of the initial EE can be saved by reusing the structural elements of the off-site prefabricated steel building. All in all, the off-site prefabricated building method enables building to be reused and reconditioned as opposed to the conventional concrete building method. Therefore, it offers better energy performance over a conventional concrete building throughout a building's lifecycle. In addition, attention shall be placed on examining advanced building techniques and methodologies, such as the way a building is designed, produced, transported, 
assembled, commissioned, operated, maintained, and reused. In addition, the IEA ECBCS Annex 50: Prefabrication System for Low Energy Renovation of Residential Buildings features European projects that focused on the development of innovative prefabricated building systems for residential building renovations [17]. The projects featured in the IEA ECBCS project showcased the state-of-the-art methods of how to achieve allocated energy targets by adopting prefabrication technologies [18].

\subsection{Embedded Energy Reduction during the Production Phase}

The reduction of EE needs to take into account each phase of the building lifecycle. In this section, methods, terminologies, and initiatives that have been developed to optimize the production efficiency, quality, and environment will be described. Lean manufacturing is a production concept developed by the Japanese automotive company Toyota and focuses on waste reduction by addressing seven types of waste, often identified by the acronym TIMWOOD: transport, inventory, motion, waiting, overproduction, over-processing and defects. Reducing one or more of these types of waste enhances productivity while simultaneously cutting down production cost and time. Some of the solutions to these waste types have been recognized internationally, such as the Poke Yoke (defects reduction) and Just in Time (JiT) (inventory storage minimization).

Poke Yoke means that all modules, components, and parts of the product are designed and structured in a way that preempts erroneous joining and assembly later in the production process. The JiT strategy is employed in the "pull" production model. "Pull" means that the quantity and quality of products manufactured depend on the customer's demands [19]. There are some examples in the construction industry such as Sekisui Heim, Daiwa House, Toyota Home and Misawa Homes, among others, that implement lean manufacturing principles in the OSM field. In addition, BIM has been recognized as one of the most powerful tools for lean construction. BIM simplifies planning, production, and organization by allowing quick and easy communication on the same platform between all the parties involved in a project (e.g., structural engineers, architects, contractors) [20].

If lean manufacturing deals with process waste, the closed-loop strategy focuses on physical construction waste, which constitutes the largest proportion of waste in most countries. Closed-loop means that the material and resources are re-used in more than one building and it affects the production and disposal phases of the building lifecycle. For instance, Toyota Home produces 5000 houses per year, keeping a large portion of the work off-site. Even with the company's strict adherence to lean construction principles, a certain amount of physical waste is unavoidable. Therefore, they sort the remaining waste into 30 categories, divided by element, in order to re-use it as soon as possible. Most construction waste is produced during the disposal phase. Urban mining is a concept that demonstrates a process for reclaiming and reusing waste materials which would otherwise have been disposed of in landfills. However, in the construction field, it is not always feasible to save material from a demolished building and the normal recycle ratio of the material saved from a conventional demolition is $55 \%$. The Japanese company Kajima developed a highly advanced deconstruction system called "Daruma". The demolishing task starts from the ground floor by detaching the structural elements from their base, after which the building is disassembled and dropped down floor by floor, with the waste materials being sorted into 23 categories. By using this method, the company managed to save up to $93 \%$ of the material from the demolition of a high rise building in the center of Tokyo in an 11-month period of time [21].

Ultimately, the closed-loop concept, rather than the cradle-to-grave approach, can be augmented through the way a building is being designed. For example, the building should be thought of systematically rather than monolithically, which should be flexible, reconfigurable, and reusable when required by the users. Building components are designed to ease logistics, installation, and building maintenance procedures that do not interfere with the building's structure and minimize the impact on the occupant during system repairs, upgrades, and maintenance. Of course, off-site prefabricated building methods offer advantages over conventional construction methods regarding system flexibility and diversity. Usually, building parts or components are only dissembled and recycled once the 
building is no longer in use. There are very few off-site prefabricated residential buildings that function as a collection of separate parts that can be disassembled or decommissioned while the building is still operational. To achieve this degree of flexibility, the concept of "open-building" will be introduced and discussed in the next section.

\subsection{Open-Building Concept}

The open-building concept—variously known as OB, S/I (support/nfill), Skeleton Housing, supports and detachable, houses that grow, etc.-is now tackling the design and construction of residential buildings. The goal of $O B$ is that a building should be designed in different levels: support structure, infill system, fit-out, and appliances. These have been reinterpreted and updated to harness the benefits of state-of-the-art industrial production, emerging information technologies, improved logistics, and changing social values and market structures. Residential $O B$ is relatively new terminology, which promotes a new cross-disciplinary approach to the design, finance, construction, fit-out, and long-term management processes of residential buildings, including mixed-use structures and teamwork. The goal is to create varied, flexible, fine-grained, and sustainable environments with the responsibility for decision making distributed to various levels. Residential OB perceives a building as levels of construction systems, which consists of support and infill systems. A support layer is a physical setting that offers the space and possibility to make dwellings with as few constraints as possible, while also requiring as little work as possible. Once erected, the support structure becomes an enclosed envelope, the common services are all installed, the site is cleared, and any disruption to local traffic is at an end. From the perspective of the community, the support appears complete. Nevertheless, to be occupied, it requires an infill level. The infill may be determined or altered for each individual household or tenant without affecting the support or base building. Infill is flexible and stationary, but less stringent than the base building or the support system [22]. In general, the systems and parts associated with the infill (fit-out) level have a lifecycle of ten to twenty years. Transformation may be occasioned by occupants' changing requirements or preferences and the infill typically comprises all components specific to the dwelling unit: partitioning and HVAC system, outlets for power, communications, security, ducts, pipes, and cables in each building.

An OB project may depreciate at the same rate as a conventional building or it may depreciate at two different rates: one for the support, another for the infill. Its parts can be upgraded or replaced with less conflict and with more controlled quality than those of a conventional building. Its subsystems, or the infill level, are also more efficiently taken down and reassembled, reconditioned, or else disposed of. In brief, when comparing the initial energy performance of an OB over conventional buildings, the energy requirement from $\mathrm{OB}$ is considerably less, especially during the renovation and building maintenance.

The project "Next 21 " is one of the best examples to demonstrate the OB concept from the design, production, and lifecycle management aspects. The project was an 18-unit experimental housing project conceived of by the Osaka Gas Corporation and was intended to explore a new urban lifestyle with certain objectives: using resources more efficiently by applying systemized construction, creating flexible layouts or structures to be able to accommodate a variety of customer demands, treating waste and drainage on-site, and minimizing the energy consumption of the building, see Figure 1 . The building consists of the skeleton (structure support), exterior cladding, interior finishing, services supplied, and all other mechanical systems, which were designed as an independent system that could be assembled, disassembled, and serviced separately, on-site. The floor-to-ceiling space was very spacious allowing service distribution equipment to be fitted above ceiling finishes and under raised floor spaces. Each unit had been designed separately by different architects with consideration for the configuration of the building skeleton. The project demonstrates that a highly flexible architectural system could be introduced. Each part of the building structure, components, and parts were divided according to their lifespan: long-lifespan components, such as beams, columns, and floor slabs, or short-lifespan components, such as partition walls, service fittings, and appliances. Each part was 
manufactured separately and assembled as different layers on-site, thereby allowing each part of the building to be maintained or removed when necessary.

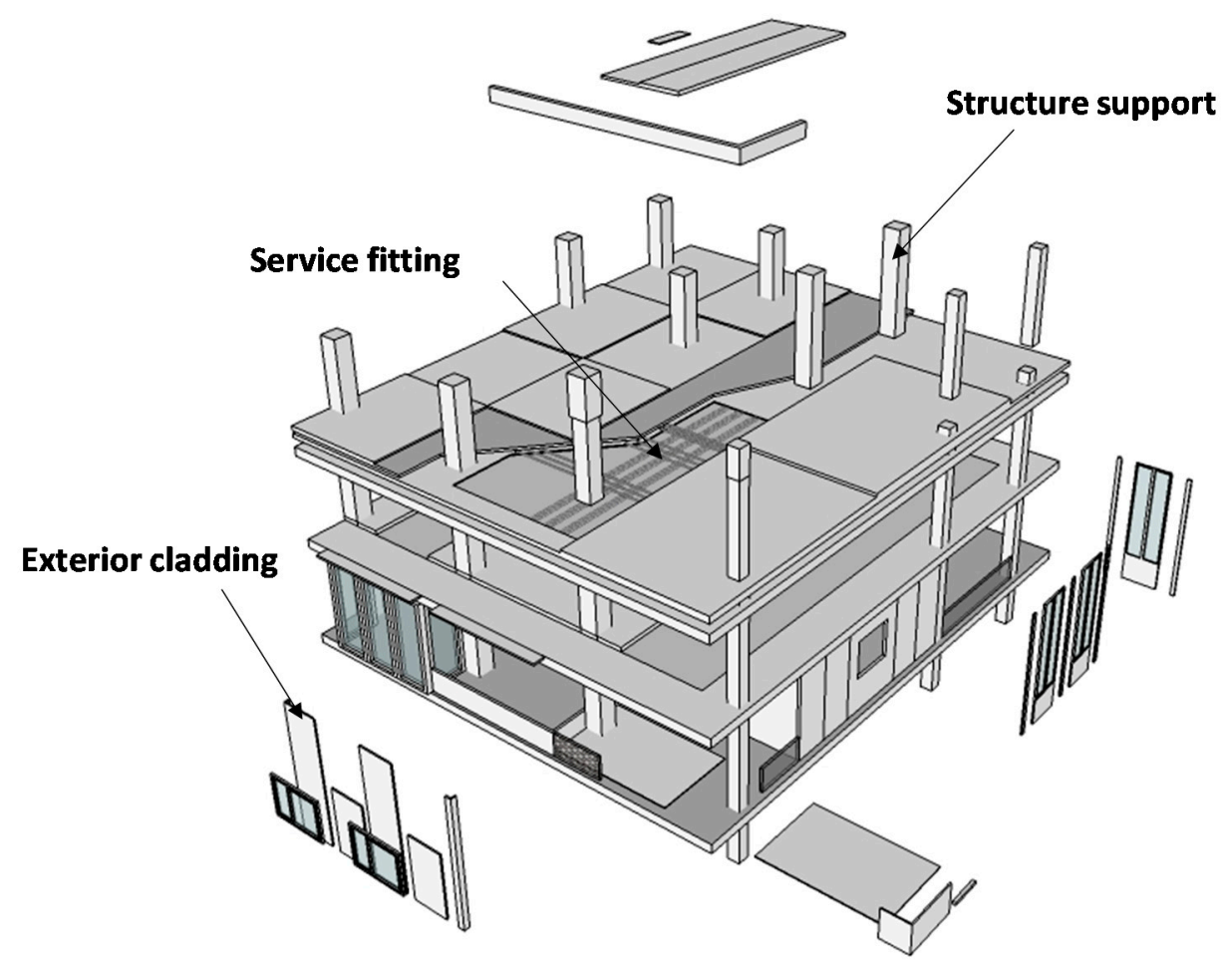

Figure 1. The "Next 21" project.

To appraise the OB concept, the building must be designed as sequential parts and components, which requires an approach that is more similar to product design than the conventional architectural design method. In the next section, the Design for X (DfX) concept will be described, which offers applicable insights when dealing with prefabricated elements production, the OB approach, and the improvement of the assembly procedure.

\subsection{Design for $X$}

Off-site prefabrication and the $\mathrm{OB}$ concept require an appropriate system design if they are to increase overall productivity, enhance the production process, and reduce the building's lifecycle energy consumption. The DfX concept provides a system of guidelines and suitable design approaches that aim to support the production, assembly, and other parameters related to the lifecycle of the product [23]. DfX includes many subcategories, but two of them shall be highlighted here: Design for Production (DfP) and Design for Assembly (DfA). They offer the relative guidelines regarding how to speed up production and simplify the assembly process, thus reducing costs, as well as improving the overall system performance.

DfP refers to a strategy which adjusts design and production parameters to each other so that a product can be efficiently manufactured and delivered. Following the DfP method, the product shape and structure is tailored to ease manufacturing on a production line. The DfP method also addresses different types of production issues during the design stage, such as the product size, type of production (e.g., flow production, shop floor production), individual production processes, throughput times, logistics, supply chain design, and degree of production automation. The design of the product is therefore critical and affects every subsequent stage of the product lifecycle. The cost of production is largely determined by the design and approximately $70 \%$ of the manufacturing costs are determined at the design stage. Therefore, an improper product design that ignores manufacture and assembly can end up infeasible or generally more expensive than it should be [24]. 
The DfA focuses on the methods of assembly for the produced parts to ease the assembly procedure as well as the minimization of assembly costs [25]. The parts are integrated into complex components and assembly is considered a critical part of the production process. DfA is critical for on-site installation planning, especially when involving machinery, various skillsets, and construction automation technologies. The development of construction robotics has demonstrated the huge potential to improve construction productivity, quality, and safety, and to address the issue of a skilled labor shortage. An overview of construction automation and robotics will be introduced, followed by a holistic approach to some of the most influential terminologies and systems, and then an evaluation of potential implications that construction automation and robotics could have on energy building development.

\subsection{Overview of Automation in Construction}

On-site construction activities are also key in defining the efficiency of a construction project. The use of off-site prefabricated components in construction is appropriate for the adoption of automation and robotics. The characteristics of prefabricated elements, such as consistent quality, weight, and connection methods make it easier for the robot to handle to ultimately increase overall productivity, improve quality and safety, and address skilled labor shortages. The potential of the prefabricated building system cannot be realized until the assembly process is dramatically improved; however, there is very limited specialized equipment that has been developed to handle industrialized building components.

Robotics technology has played a significant role in the manufacturing industry and the automation of production facilities, especially in Japan, where robotics has contributed extensively to the country's economic growth and the industrialization of the Japanese construction industry. In the early 1980s, Japan's construction industry started to face a shortage of skilled workers because the conventional construction sites were considered dirty, dangerous, and difficult. The construction industry had begun to fall behind the manufacturing industry and it was therefore essential to improve working conditions and productivity. In 1983, Shimizu developed the world's first construction robot, "SSR-1" and its main duty was spraying fireproofing material onto steel elements. Industrialized construction sites were similar to an on-site factory, coordinating each work task and team to ensure maximized production (construction) efficiency. There were over 150 types of single-task construction robots developed; however, applying single-task robots did not improve the overall productivity as expected because of the extensive preparation procedures and high R\&D costs. The complete potential of robotics cannot be realized until the construction process is automated and building components are designed and adapted to robotic on-site operations [26].

A special design principle is needed when implementing construction automation and robotic technologies. This is due to the fact that conventional buildings have been designed without consideration for how to incorporate robotic assembly methods. In 1988, the notion of robot-oriented de-sign (ROD) was proposed by Dr. Bock and later served as the principle for automated construction and robot-based construction sites around the world. The ROD concept emphasizes the idea that during final on-site construction processes, all design parameters should have been considered at the earliest design and production stages. The building components need to be designed to be easily handled by robots during the assembly phase. When developing robotic technology for the construction sector, it is far more diverse and complicated than the operation in manufacturing plants [26].

In principle, the building system should be designed not only for robot-oriented construction but also for maintainability, reliability, stability, serviceability, safety, and aesthetics. This can be achieved by coordinating production-related engineers with planners and architects. Standardization is a critical aspect of ROD, as the same parts and operations can be used for similar kinds of buildings. Specifications and building systems should be designed as kits that consist of highly differentiated parts that can fulfil any functional requirement and regional building code [26]. 
Construction automation and robotic technologies offer an alternative on-site assembly method. The autonomous method has huge implications for how a building is designed, constructed, and later on, maintained, and decommissioned. In this paper, conceptual designs of a robotic assembly system will be proposed to analyze the applicability of using automation during building assembly as well as during maintenance tasks.

\section{Methodology}

The research attempts to tackle how to improve the overall building energy performance from an alternative perspective. First, to evaluate the added value from adopting prefabricated construction technology, if prefabrication can improve energy performance over the building lifecycle. Second, to investigate whether energy production technology integration will ease the installation process, thus making a building more accessible for future maintenance and enhancing OE performance. Third, to explore how to implement automation and robotics technology in the building installation process, thus improving building quality, efficiency, safety, and potentially augmenting the traditional building industry as a whole. The selected case studies provide a comprehensive insight into the state-of-the-art research in energy production product integration, prefabrication, and automated installation technology, and are focused on either new builds or renovation projects.

\subsection{Case Studies}

\subsubsection{BERTIM}

BERTIM was funded by the European Union's Horizon 2020 Research and Innovation Programme under Grant Agreement No. 636984 [27]. Augmenting the overall efficiency of building renovation processes and offering an affordable solution to reducing energy consumption during a building's renovation phase became popular topics in the scientific research community. The objectives of the project were to investigate and improve the existing renovation processes by using prefabricated timber façade modules and to apply automation technology in the production and installation task systematically. The prefabricated timber façade module is highly energy efficient and is equipped with insulation materials. Other features and appliances, such as windows, energy performance systems, and an HVAC system, were integrated into the module. Due to the nature of off-site prefabrication, on-site installation tasks were minimized, reducing disturbances for the occupants. In addition, the project also adopted advance BIM technology that integrated with CAD/CAM applications throughout the data collection, production, and installation process.

BERTIM addressed each task within the renovation phase and, in total, two sub-systems were proposed to be included in the 2D module configuration: the manufacturing process and the installation process shown in Figure 2. To achieve an affordable solution for manufacturers or installation companies in a wider market, the project developed a systematic method to ensure the adaptability of the hardware and software and embraced a close collocation between research institutions and industry practitioners.

The irregular geometry of the existing building imposed many challenges on the research team during the project. Some of the existing building had developed uneven surfaces over the years, which meant that the connectors of the prefabricated façade module needed to be calibrated and be able to adjust to various façade conditions. Producing and integrating a versatile connector for an off-site prefabricated façade module, however, is very challenging and time-consuming. A researcher at the Technical University of Munich (TUM), therefore, proposed an innovative installation procedure and a highly customized connector to tackle the issue. The connector consists of three parts: one that connects to the building façade, one that connects with the module, and one that connects the interface section between the two parts, see Figure 3. The key aspect of the installation task was to make sure the connector was fixed in the right position. The overall installation procedure is described below.

- Scanning the existing building façade with a total station (TS) that ensures the alignment of the fixing position and installing the connector onto the façade, guided by the TS. 
- Producing the interface between the existing building and the prefabricated module on-site by a 3D printer and then installing the pre-installed connector.

- Manufacturing the prefabricated module based on the on-site measurement and then delivering and installing the connector and the interface part.

- Installing the prefabricated module at the correct position.

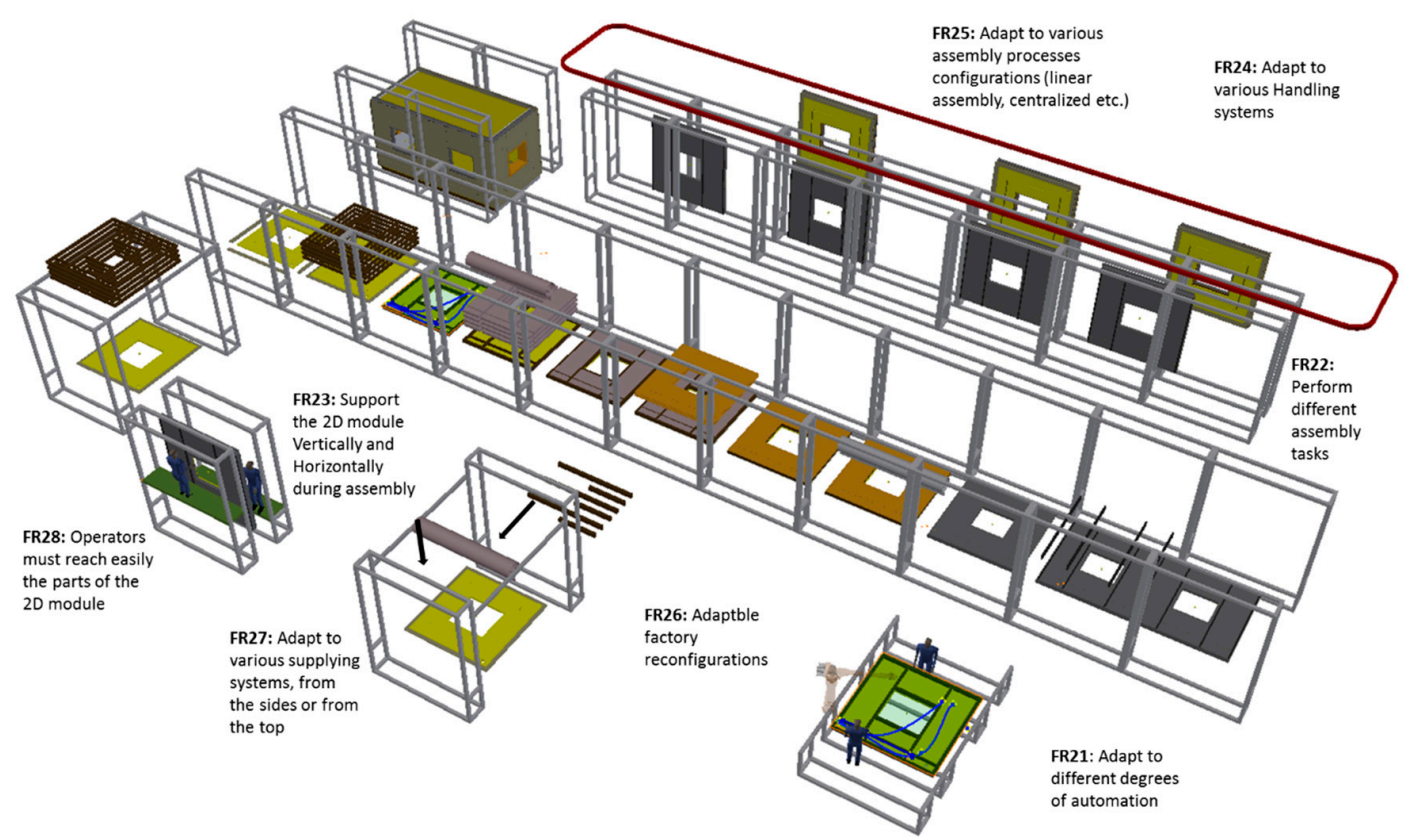

Figure 2. BERTIM manufacturing process.

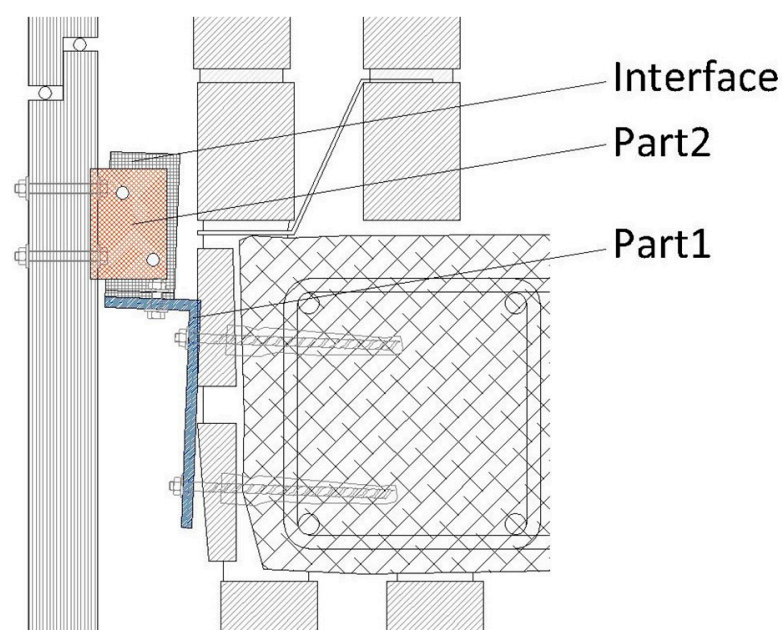

Figure 3. Connector and interface design.

The logistics, installation process, and thermal performance of the BERTIM were demonstrated through a pilot project using a 2-story brick building with a floor area of approximately $500 \mathrm{~m}^{2}$. The pilot building is located in one of Tecnalia's testing facilities in Derio, Spain. During the pilot testing stage, the research team investigated the energy that would be required and the potential savings of using the aforementioned highly integrated prefabricated modules, with an innovative management system for HVAC, lighting, energy production products, and other appliances.

The thermal resistance values before and after installing the BERTIM prefabricated façade module were measured and compared and the results were quite stunning: the post-installation value was measured at $5.07 \mathrm{~m}^{2} \mathrm{~K} / \mathrm{W}$ and was $0.53 \mathrm{~m}^{2} \mathrm{~K} / \mathrm{W}$ prior to installation. The BERTIM project 
demonstrates the proof of concept (PoC) of using a prefabricated façade module for renovation purposes. The installation process and thermal performance proved to be more effective and efficient than the conventional method and even though the potential reduction of EE, REE, and DE was not discussed in the project, the overall outcome of the project is encouraging. The question that remains is whether automation and robotics technology provide a solution to increasing installation speed, accuracy, safety, and, in the long term, reducing the energy required when repairing and maintaining structures. The next case study offers an insight into the implementation of automation and robotics technology in a construction-related application.

\subsubsection{Hephaestus}

Hephaestus was also commissioned by the European Union's Horizon 2020 Research and Innovation Programme under Grant Agreement No. 732513 [28]. The conventional glazing curtain wall installation method is time-consuming, highly risky, and labor-intensive. This project provides an innovative concept of installing an off-site manufactured curtain wall module (CWM) by adopting a cable-driven parallel robot (CDPR).

In brief, the Hephaestus system consists of five sub-systems: the cable robot structure, the CDPR body, the modular end-effector (MEE), the loading system, and the control system. The cable robot structure compresses four sets of winches and pulleys that are situated on the top level of the installation site, and then another additional four sets of winches and pulleys and cable routing systems are located on the ground level. The top installation position of the cable robot structure depends on the overall construction schedule. If the CWM is scheduled to be installed once the building structure is completed, then the cable robot structure will be installed on the roof structure. Alternatively, it can be installed on the finished floor level; however, the additional force caused by the CDPR needs to be taken into consideration when designing the structural specification of the retaining floor. The CDPR body provides supporting structures that connect with the cables as well as where the MEE is installed. The MEE is divided into upper and lower MEE. The upper MEE includes a robotic arm, tool interchanging station, and installation material magazine, while the lower MEE consists of the concrete slab clamps and a CWM vacuum system. The MEE can operate in an outdoor environment while retaining its high level of accuracy. The main functions of the upper MEE are detecting rebar positions, drilling concrete slabs, installing installation brackets, inserting anchors to the correct positions, and fastening anchor bolts. The MEE should be able to transition from one task to another if the interchangeable end-effector feature is enabled. Once the CWM has been unloaded from the lorries, the loading system consists of a material stacking frame or picking position where the CWM is located. The control system, in this project the CDPR, is controlled by a Beckhoff TWINCAT3 programmable logic controller (PLC) program.

The proposed autonomous CWM installation process is comprised of the following steps: delivering the CWM and setting up the loading area, scanning the rebar position across the installation area, drilling holes in the concrete slab, positioning the anchors and the brackets, tightening the bolts and nuts, picking and placing the CWM to the correct installation position, and inspecting the installation position. The on-site pilot testing was carried out from late December 2019 to early January 2020 at the Tecnalia facilities in Derio, Basque Country, Spain (Figure 4). During the pilot testing, rigorous examinations were conducted to further validate the applicability and the constraints of the Hephaestus concepts. Primarily, the consortium conducted tests on:

- The overall stability of the CDPR structure;

- The configuration of the robotic system, in terms of hardware and software integration and the Human-Machine Interface (HMI) system;

- The function of onboard sensors and cameras;

- The function of the end-effector, including drilling, positioning, anchoring, and fastening;

- Evaluation of the precision of holes, anchor position, pick-up precision of the CWM and anchorage; 
- Testing the operational condition under various weather conditions, for example, rain or windy conditions.
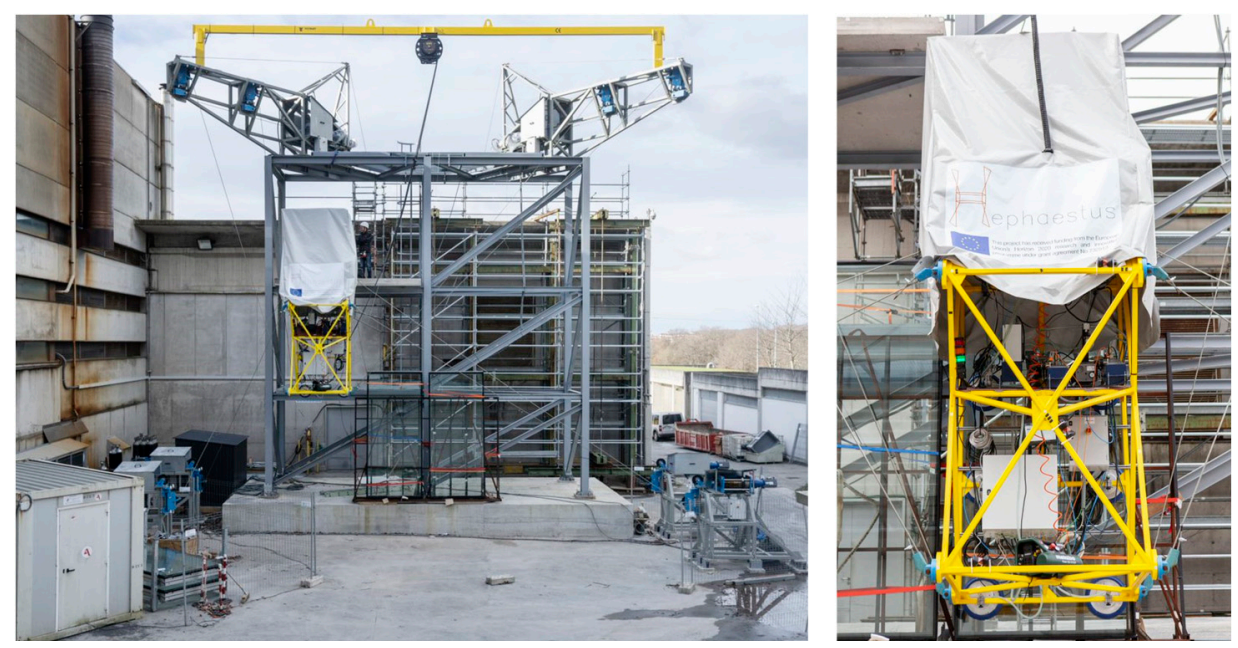

Figure 4. On-site pilot testing of the cable-driven parallel robot (CDPR).

During this phase of pilot testing, the overall function of the Hephaestus system was studied and the pilot test demonstrated the potential of using the CDPR in CWM installation task. However, there are still many challenges, such as the calibration time for the system being too long to be economically accepted, and the system being too heavy and too large to be installed on buildings that are not designed with the consideration of the CDPR being used. Nevertheless, the project presents a systematic approach on how to implement automation and robotic technologies in the context of CWM installation, through an interdisciplinary approach.

\subsubsection{ZERO-PLUS and Freescoo System}

The Freescoo HVAC system was developed by SolarInvent from Italy. It is an innovative compact desiccant evaporative cooling air conditioning system designed for ventilation, cooling, dehumidification, and heating of buildings in the residential as well as commercial sectors. Originally, the Freescoo system was developed and evolved in the ZERO-PLUS project, which was commissioned by the European Union's Horizon 2020 Research and Innovation Programme under Grant Agreement No. 678407 [29]. In brief, the overall aim of the ZERO-PLUS project is to achieve near-zero and positive energy settlement by using innovative, economical energy production technologies in Europe. There were four case studies in the project-the UK, France, Italy, and Cyprus, and each represents a unique climate region to validate if the ZERO-PLUS solution can improve the overall efficiency of energy conservation and generation in the settlement level while reducing costs throughout each project phase. The project team from TUM have been working closely with SolarInvent and other project partners to overlook the system configuration and to make sure the system can be easily integrated with the building structure (external wall), as well as easily installed, repaired, and maintained. The Freescoo system was only adopted in the Cyprus case study so only the potential improvements in the aspects of installation and building integration of the Freescoo system, as well as the lessons learned from the case study, will be addressed.

The Freescoo system continually evolved over the course of the project and the design changed from two separate modules (an evaporative (EVA) module and an adsorption (ADS) module) to a compacted single-unit design [30], see Figure 5. 

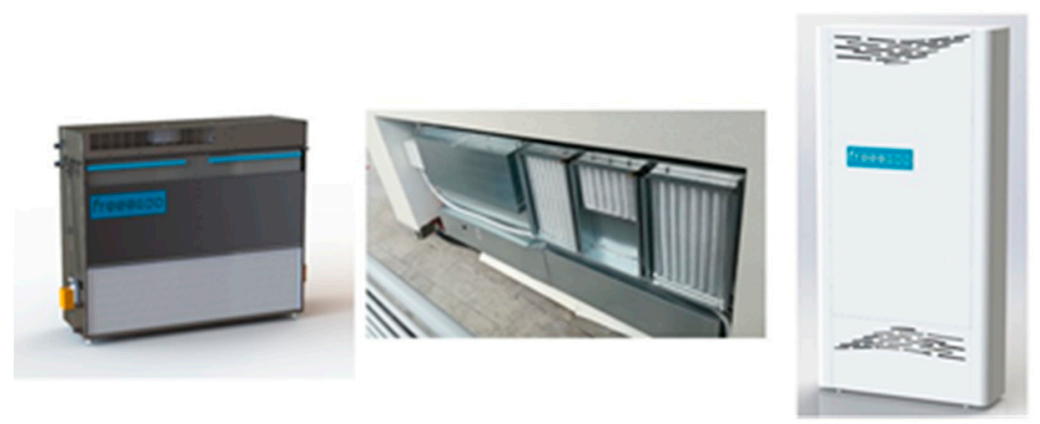

Figure 5. Evolution of the Freescoo system.

The latest design features a compact vertical design, of which the current width is $1001 \mathrm{~mm}$, the height $-1986 \mathrm{~mm}$, and the depth $-286 \mathrm{~mm}$. The key technical data is shown in Table 1 . The Freescoo system was designed to be installed externally, internally, or fully integrated with the building envelope. The Cyprus case study comprised a weather station at the Cyprus Institute (CYI) premises in Nicosia, see Figure 6. The weather station was constructed with a 3D volumetric method. Given the circumstances, the project team decided to adopt the external installation method. Even though the Freescoo system was installed externally, the project team proposed an installation wall solution that also demonstrated the potential of the system if it was fully integrated with the building envelope.

Table 1. Freescoo façade 3.0 technical data.

\begin{tabular}{lc}
\hline \multicolumn{2}{c}{ Cooling Performance ${ }^{1}$} \\
\hline Total cooling power due to the handling of ambient air & $2.5 \mathrm{~kW}$ \\
Total cooling power delivered to the building & $2.2 \mathrm{~kW}$ \\
Return air temperature from the building at design condition & $27^{\circ} \mathrm{C}$ \\
Supply air temperature at design condition & $19^{\circ} \mathrm{C}$ \\
Maximum air flow rate & $700 \mathrm{~m}^{3} / \mathrm{h}$ \\
Percentage of fresh air (standard setting) ${ }^{2}$ & $10 \%$ \\
Heat required & $2.7 \mathrm{~kW}$ \\
Inlet temperature at design condition & $70{ }^{\circ} \mathrm{C}$ \\
Outlet temperature at design condition & $65^{\circ} \mathrm{C}$ \\
Water flow rate & $447 \mathrm{~kg} / \mathrm{h}$ \\
Power absorbed & $0.180 \mathrm{~kW}$ \\
Internal pressure drop & $9 \mathrm{kPa}$ \\
Water consumption & $21 / \mathrm{kWh}$ \\
Rated EER & 13.8 \\
\hline & \\
\hline Total heating power delivered to the building & $2.0 \mathrm{~kW}$ \\
Heat required & $2.0 \mathrm{~kW}$ \\
Inlet temperature at design condition & $50{ }^{\circ} \mathrm{C}$ \\
Outlet temperature at design condition & $45^{\circ} \mathrm{C}$ \\
Water flow rate & $350 \mathrm{~kg} / \mathrm{h}$ \\
Internal pressure drop & $9 \mathrm{kPa}$ \\
Power absorbed & $0.070 \mathrm{~kW}$ \\
Air flow rate & $470 \mathrm{~m} / \mathrm{h}$ \\
Percentage of fresh air & $10 \%$ \\
\hline
\end{tabular}

${ }^{1}$ Design conditions: outdoor air at $35^{\circ} \mathrm{C}$ and $16 \mathrm{~kg} / \mathrm{kg}$, indoor air at $27^{\circ} \mathrm{C}$ and $10 \mathrm{~kg} / \mathrm{kg}$, regeneration temperature of $70{ }^{\circ} \mathrm{C}$ - partial recirculation mode ( $10 \%$ of fresh air). ${ }^{2}$ The flow rate of fresh air can be varied according to the specific need, ${ }^{3}$ Design conditions: outdoor air $0{ }^{\circ} \mathrm{C}$ and $3 \mathrm{~kg} / \mathrm{kg}$, indoor air $20^{\circ} \mathrm{C}$ and $3 \mathrm{~kg} / \mathrm{kg}$, heat temperature of $65^{\circ} \mathrm{C}$-ventilation mode. 

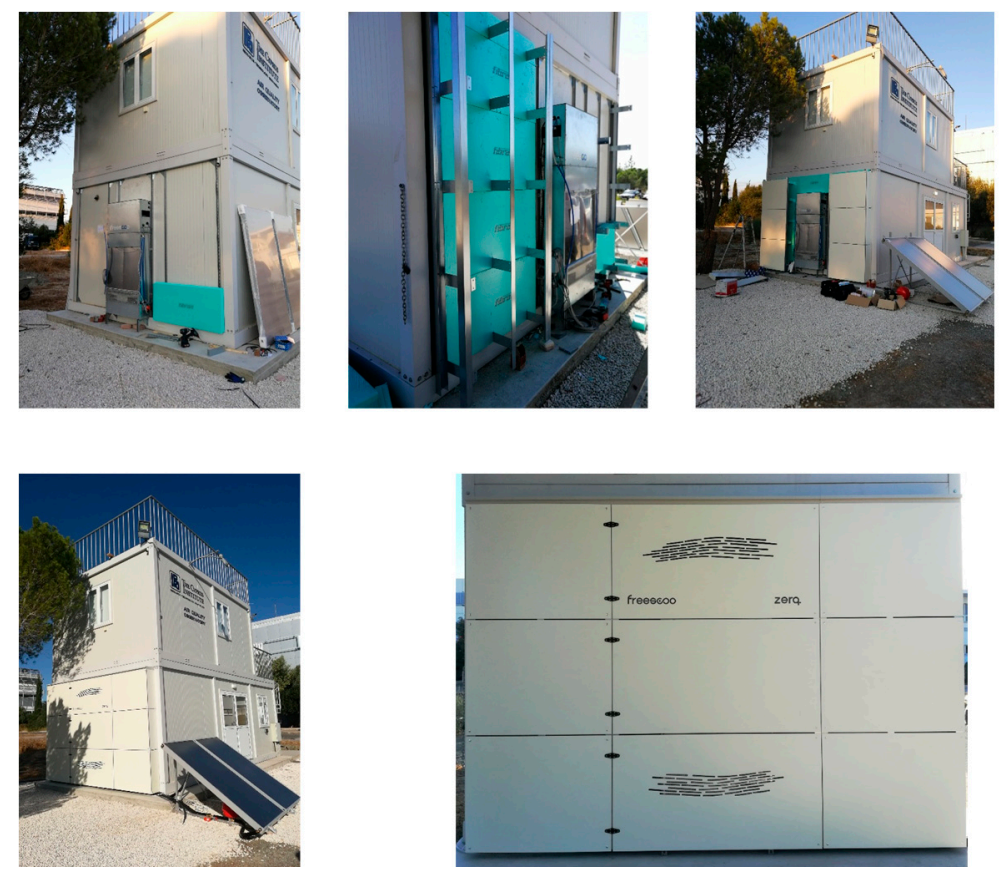

Figure 6. Installation wall assembly.

The installation wall consists of galvanized strut channels, fixture profiles, sloping roof elements, insulation panels, high-pressure compact laminate (HPL) cladding panels, and a maintenance access door. All the components were prefabricated in Italy and later delivered to Cyprus. Encouragingly, most of the prefabricated parts and components shipped from Italy were fitted perfectly or with very little deviation. The installation took four days: three days for the installation wall construction and one day for the system installation, calibration, and commissioning. However, despite the successful installation, the project team identified several challenges that needed to be addressed prior to the commercialization of the system. Firstly, the Freescoo system is too heavy for manual handling. Secondly, the installation time was slow, which may impose a negative impact on the mass adoption of the product, especially if the product would eventually achieve an economy of scale. Subsequently, the author recommends a PoC installation method that will improve the installation process, maximize the system performance while improving accessibility in case of repair or maintenance, and be aesthetically appealing. Furthermore, the proposed system and the accompanying installation procedure should expose the pros and cons of adopting off-site prefabrication, automation, and robotics technology, as well as helping predict other implications for the reduction of energy required throughout the building's lifecycle.

\subsection{System Development}

Based on the experiences from the aforementioned projects and theories, a building system is a set of interconnected building elements that act together to form a building that performs many functions. In this section, an integrated energy production modular system will be illustrated, which demonstrates flexibility in design, efficiency in installation, and lifecycle management. Two scenarios were proposed: external installation for a new-build project and external installation for a renovation project.

\subsubsection{Scenario One}

In the scenario for new-build projects, the integrated façade system consists of three components: the interior partition wall system, the suspended modular floor system, and the integrated façade system. By following the $\mathrm{OB}$ concept, the operational period of the building can be maximized and building maintenance and alteration become less complicated. 
The interior partition wall system is constructed with lightweight galvanized steel, with sound insulation panels, and covered with gypsum plasterboard. Conventionally, when performing an interior alteration, the wall finishing is removed and the electrical wires are pulled out of the plaster walls and then new electrical cables must be installed and the wall is then replastered. These conventional processes are time-consuming, dirty, and labor-intensive. The proposed versatile design allows the system to accommodate and ease the installation of various services. In this case, workers only need to remove the plasterboard before accessing the service layer, such as cables. The holes on the steel profile enable cables to run free from one panel to another in any direction or orientation. In addition, when disassembled, the lightweight galvanized steel panel can be recycled and reused.

The suspended floor system was inspired by the modular floor system proposed by Kendall [31]. The base structure of the suspended floor is made of fireproofing composite material that can be cut into shapes that adjust to the internal layout of the building. The upper finishing part consists of standard hard floor finishing material. The most profound feature is the void in between the floor finishing and the floor base structure, which can be used to accommodate service pipes and other fittings. The advantage of this feature is to minimize the disturbances while conducting building renovation and maintenance tasks because the service layer, such as the pipes and cables, is easily accessible.

The integrated façade system consists of five sub-components: precast concrete (PC) non-load-bearing wall panel, insulation panel, steel installation channel, cladding panel, and the Freescoo system, see Figure 7. In principle, the integrated façade system is prefabricated off-site and once it has been delivered on-site, it can be installed by conventional means, such as being hoisted by a tower crane or a spider crane. Alternatively, the non-load-bearing wall panel can be made of steel or wooden frames, which would depend on the building type and the choices of the architect, see Figure 8.

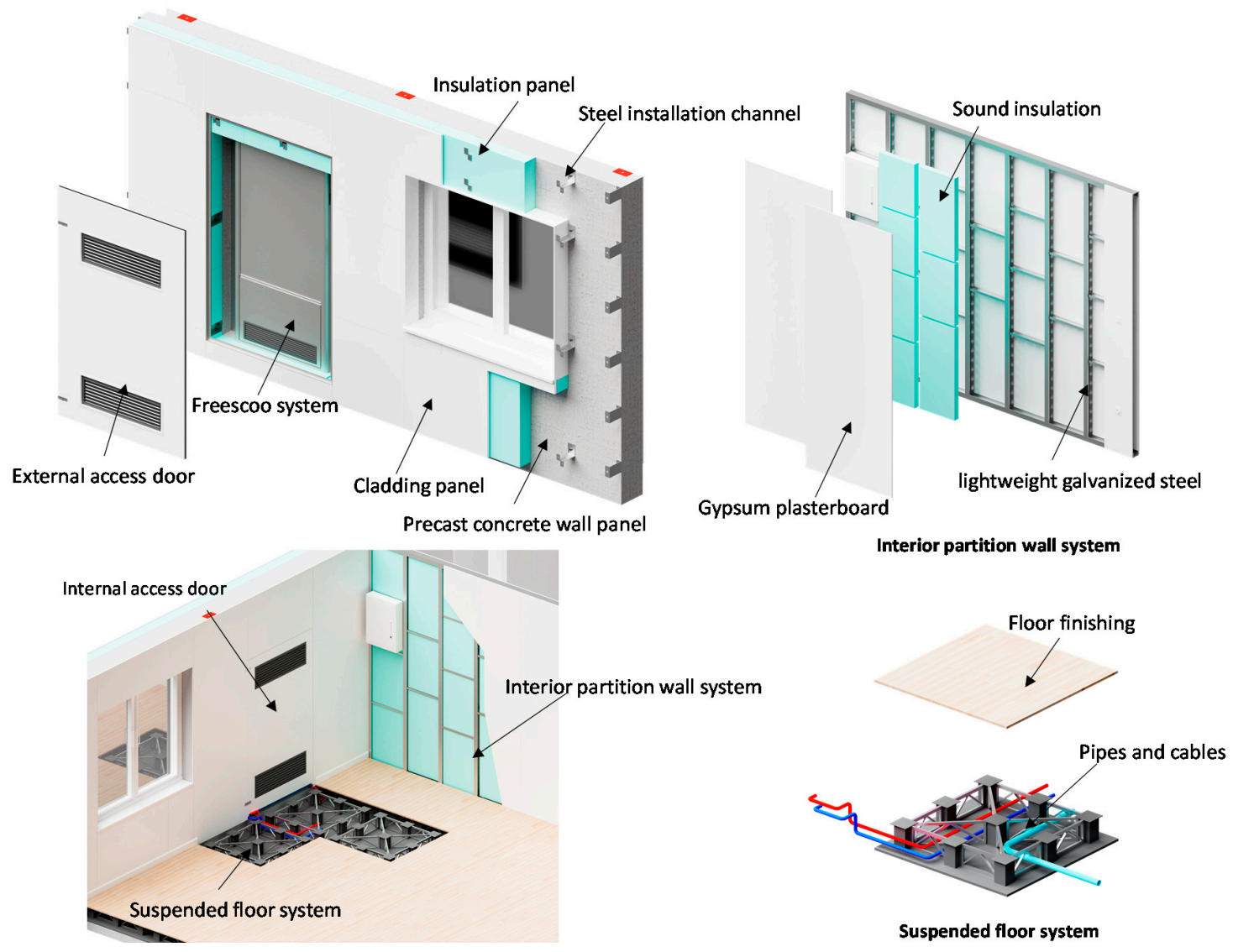

Figure 7. The integrated façade system. 

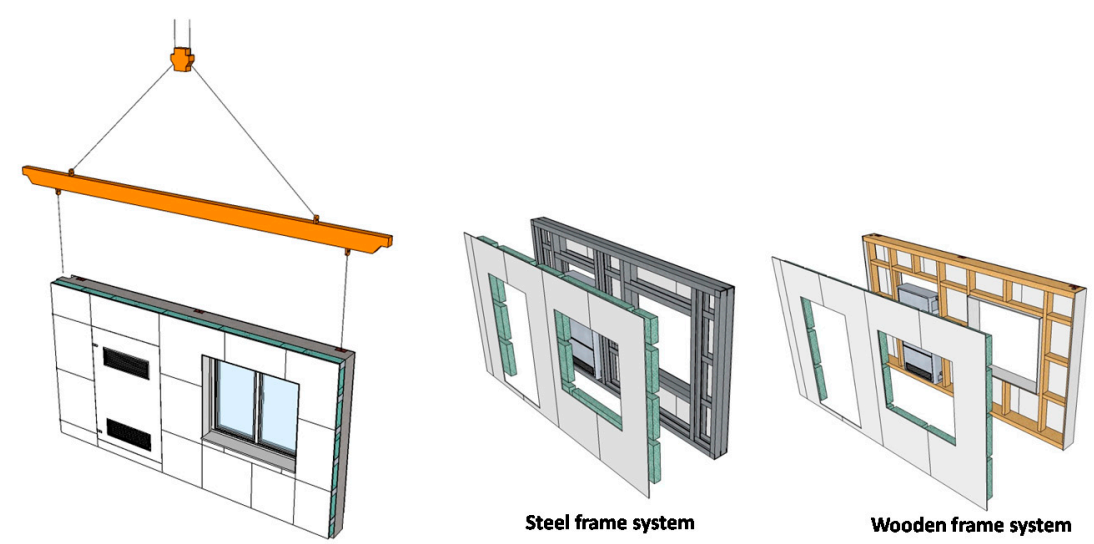

Figure 8. Non-load bearing wall panel designs.

The connector design was inspired by a system developed for steel frame residential buildings, which was originally certified and commercialized in China, see Figure 9. The connector consists of two parts: the upper part lifts the panel while the bottom part carries the weight of the panel. The connector provides a dry connection method, which eases the installation process, according to the project data in China. On average, each panel can be installed within $20 \mathrm{~min}$ and the installation speed improves on a learning curve. Due to the Freescoo system being fully integrated into the wall, the design would allow the system to be accessed from the interior space by a door when repair or maintenance is required. In addition, to improve the acoustic performance, a layer of sound insulation should be applied to the back of the maintenance door.

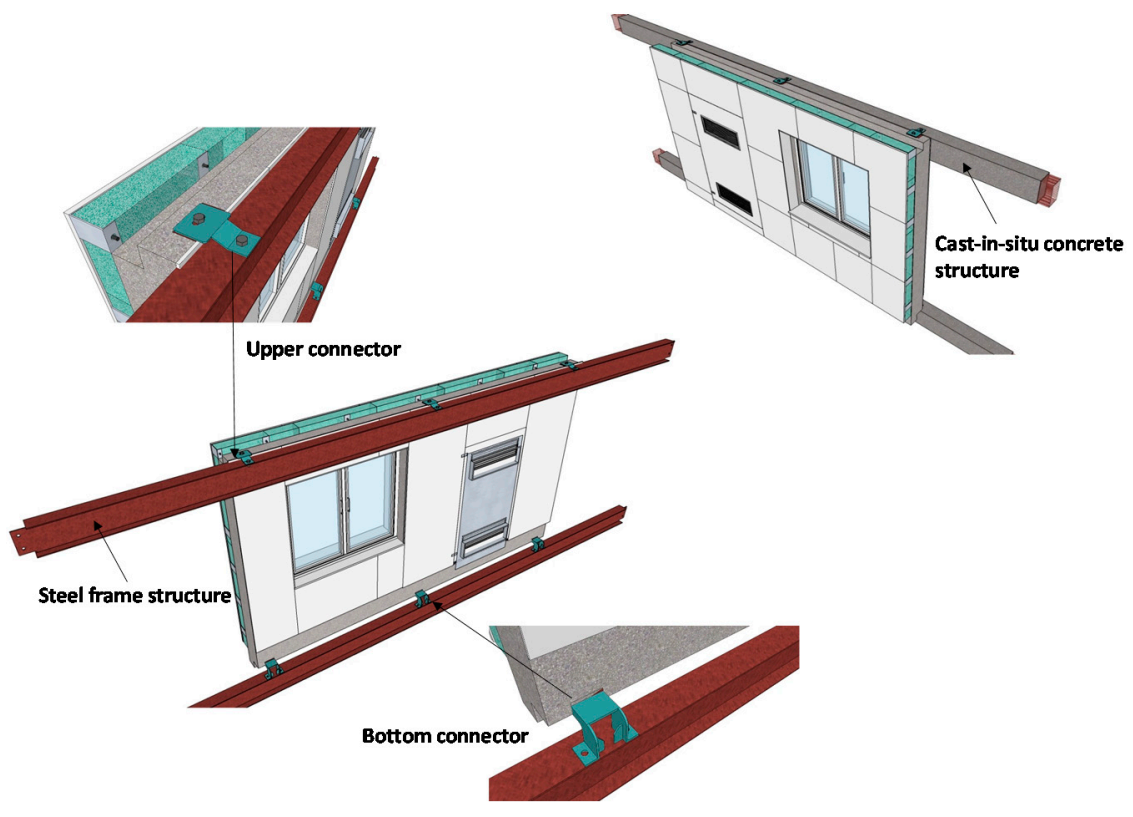

Figure 9. Connector design for the non-load bearing wall panel.

\subsubsection{Scenario Two}

The building renovation market in Europe is continuing to grow, triggered by the increasing demand for achieving a satisfactory renovation rate. The second scenario is based on a renovation project and the integrated façade system would be installed externally on the existing building façade. The construction renovation sector in the EU has experienced severe labor shortages, declining efficiency, increasing costs, and unsatisfactory safety records. The Hephaestus solution can potentially upskill the existing labor force and increase productivity, quality, and on-site safety. In this scenario, 
a semi-automated installation method is proposed, which was inspired by the Hephaestus project, and used for the renovation task along with vertical building planes. Furthermore, the Freescoo system is integrated with the façade system to demonstrate the rapid installation potential once the system reaches a certain economy of scale.

The integrated façade system consists of four components, including the steel installation channel, the insulation panel, the cladding panel, and the Freescoo system, see Figure 10. The conventional façade renovation task was thoroughly investigated and some tasks were considered not feasible to be automated, such as the preparation task, the insulation panel installation, and the cladding panel insulation. Task breakdown, human performance, and human and robot allocation of function analyses were conducted. During the analysis, the human core performance, competence, and constraints within the façade renovation task were evaluated, which assisted the system designer in predicting which kind of motion, sensing, information flow, and decision-making the robotic system would potentially preform and which would be allocated to human workers.
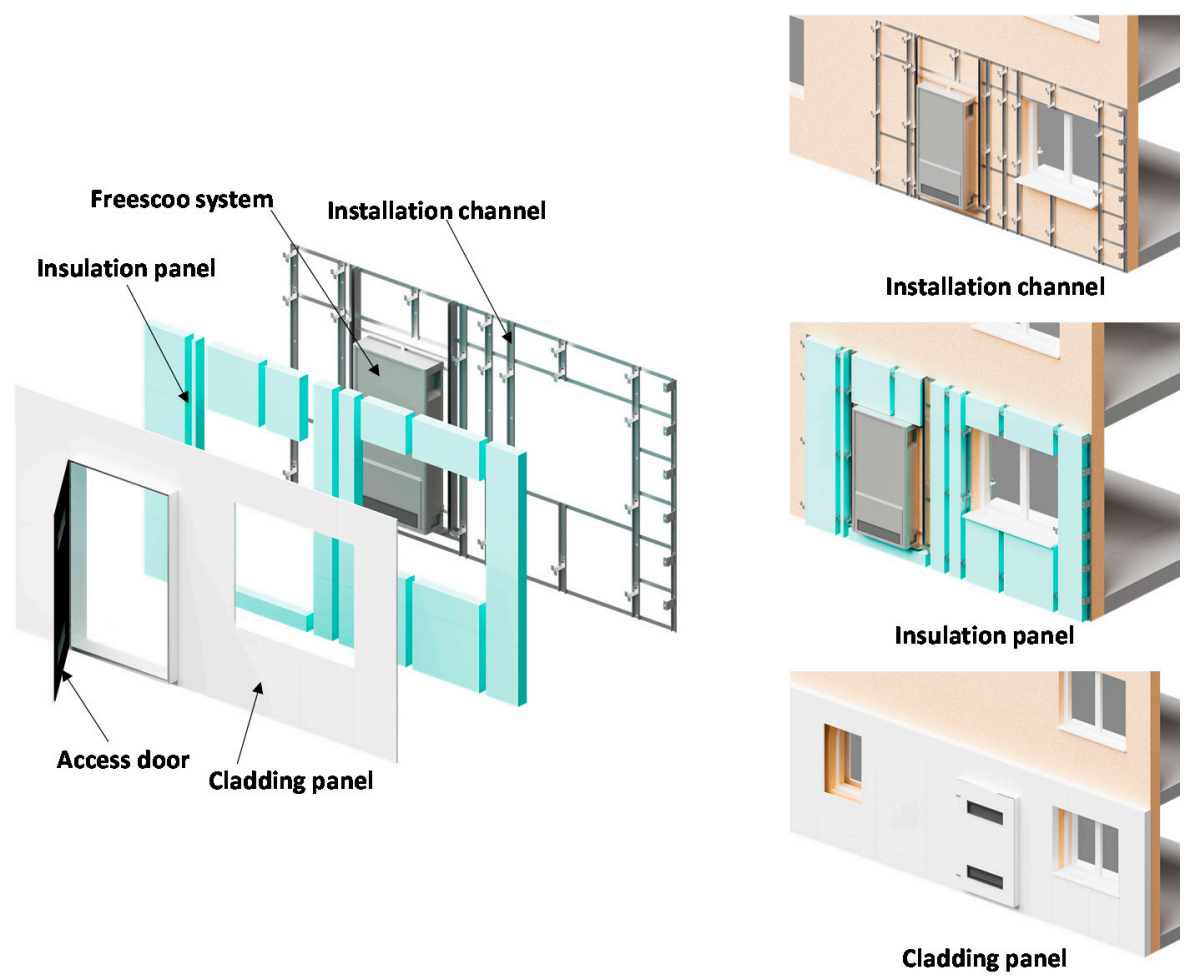

Figure 10. The proposed integrated façade system.

As shown in Figure 11, the design of the proposed CDPR is similar to that of the Hephaestus project. The cable structures, cable routing system, and four sets of winches and pulleys are situated on the roof. The lower supporting structures with the other four sets of winches and pulleys and cable routing systems are located on the ground level. On the ground level, there is also a dedicated loading area where lorries loading and unloading the steel installation channel, picking station, insulation panel, and cladding panel are located. The proposed CDPR consists of three main components: an interchangeable MEE, the mobile platform, and the working platform. In this scenario, the interchangeable MEE has two functions: clamping the steel installation frame and fastening the installation frame onto the wall, see Figure 12. 


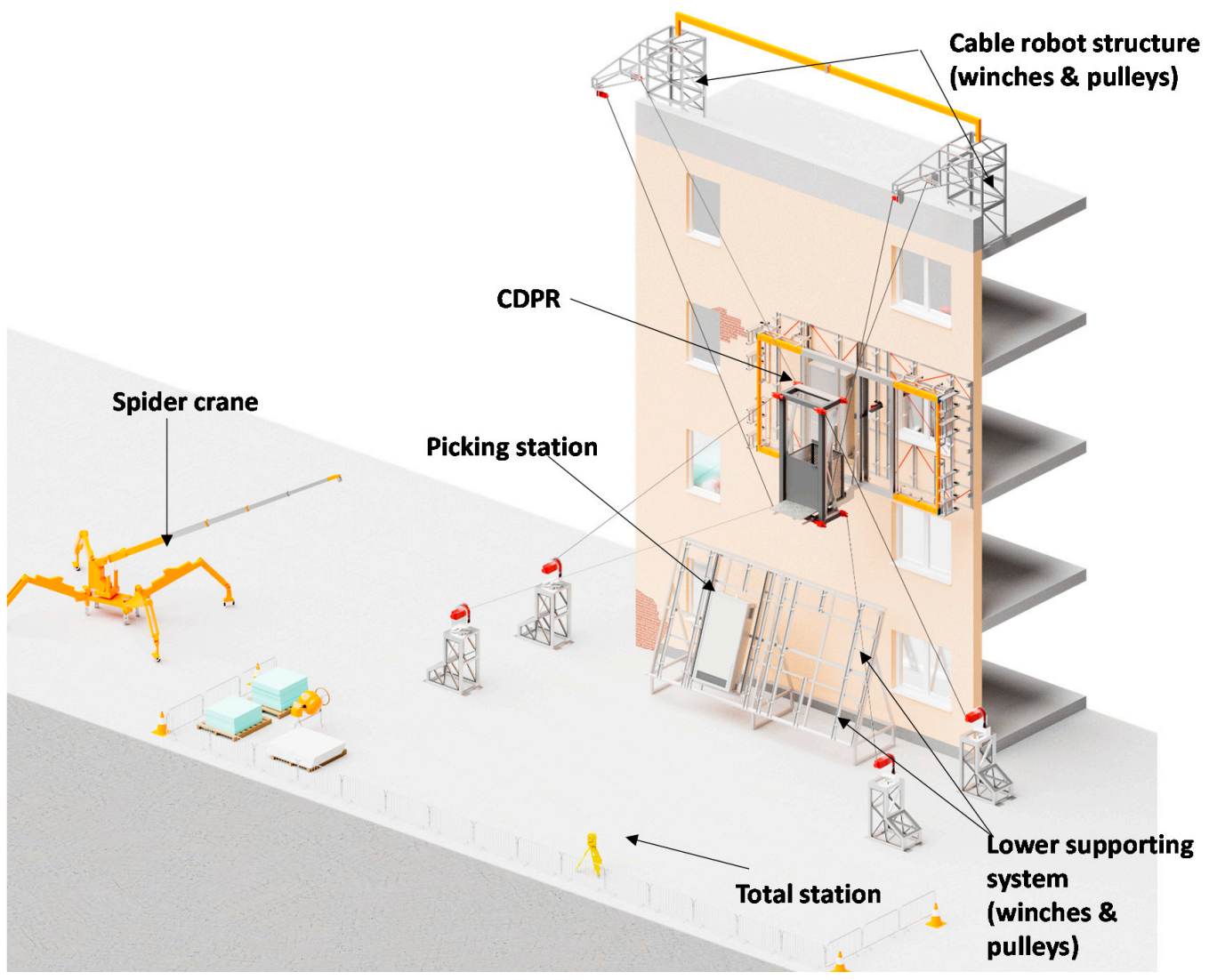

Figure 11. The proposed CDPR for building renovation.
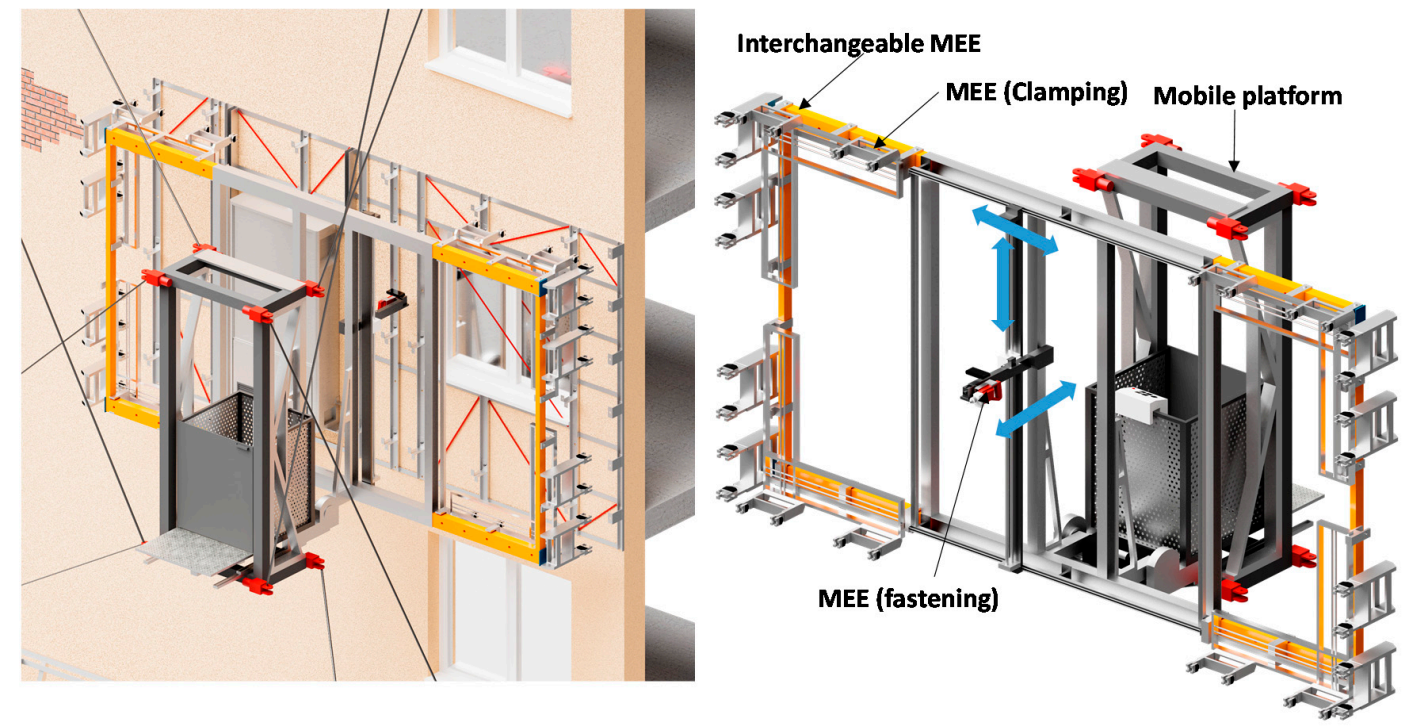

Figure 12. The proposed CDPR for building renovation.

The installation procedure is described below, see also Figure 13.

1. Preparing the wall and making the vent openings able to accommodate the Freescoo system.

2. Installing the cable robot structure on the roof and installing the winches, pulleys, and supporting systems on the floor.

3. Setting up the pickup position and the loading platform. Due to the weight of the steel installation channel, a mobile spider crane is required. 
4. Calibrating the CDPR and setting up the total station for CDPR positioning and tracking.

5. Picking and placing the installation channel, which will be positioned to the correct location and the MEE shall hold it in place while the fastening end-effector secures the steel installation channel on the wall. In order for the installation channel to remain stable during the hoisting process, steel bracing bars are temporarily equipped.

6. Removing the MEE and activating the working platform.

7. Removing the temporary steel bracing bar and installing the insulation panel.

8. Installing the cladding panel.

It is encouraging to see that the proposed semi-automated solution can be implemented in this scenario, which potentially augments installation efficiency, safety, and quality. However, there are constraints when applying the solution to an existing building and these challenges will be explained in the later section.

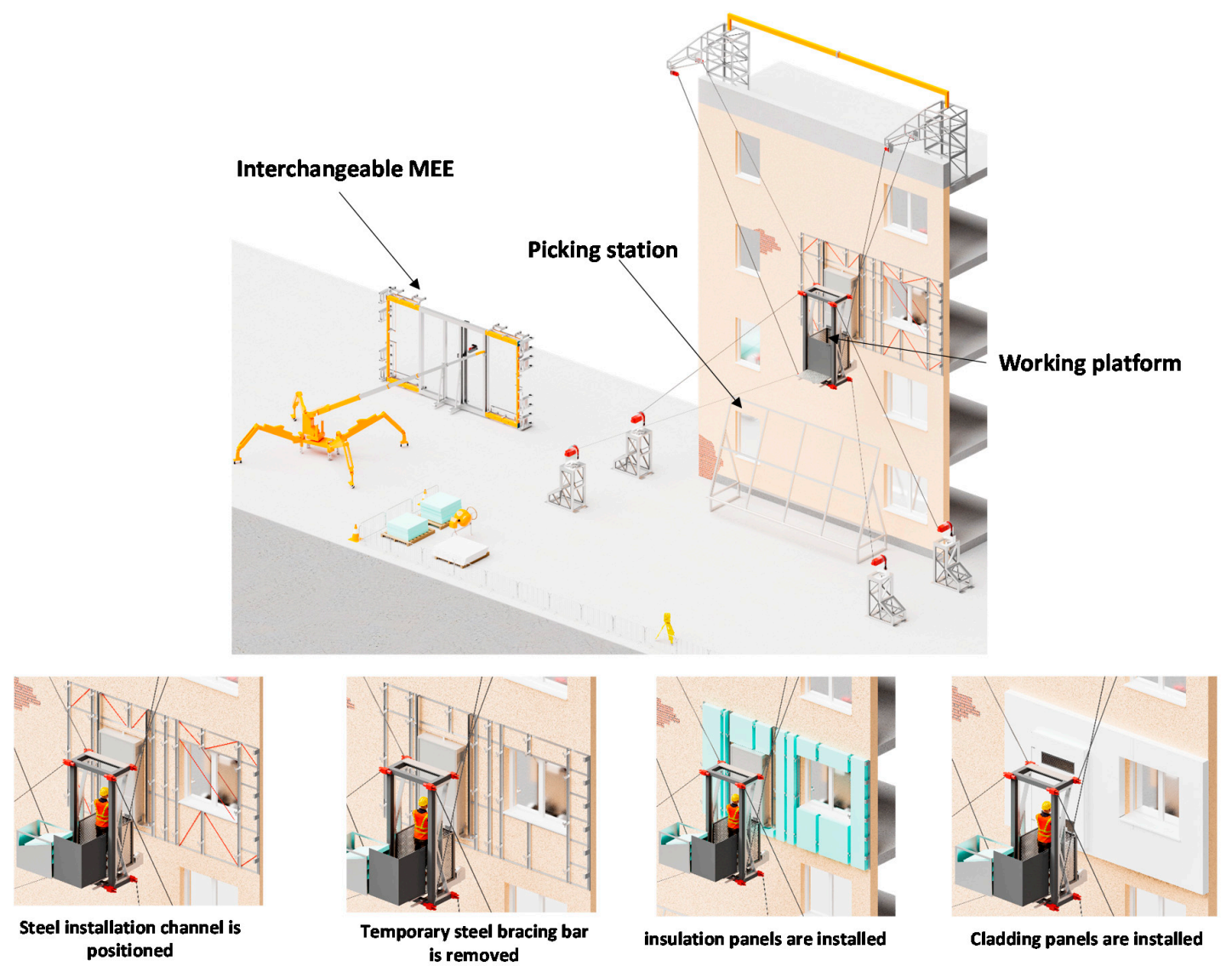

Figure 13. Installation process of the integrated façade system steps 6-8.

\section{Results and Discussion}

The proposed integrated building system and the semi-automated installation method were inspired by the OB concept, ZERO-PLUS project, and the Hephaestus project, respectively. Together, the proposed systems in both scenarios demonstrate that the adoption of prefabricated building systems, the integration of energy production technology, and construction automation technology can have a profound impact on building energy performance from an alternative perspective. Prefabrication can improve the installation process during the construction phase and offer a high quality of building as an end product. Thus, with better quality, flexibility can improve the living standard, reduce repair, and routine maintenance. The robot-enabled assembly system, such as the proposed CDPR, corresponds with the proposed prefabricated building system that drastically improves the installation process. 
There are many services where buildings typically consume energy during their operational phase. When considering energy efficiency directives in buildings, the main services are HVAC systems, which are used to keep comfort levels within the building at an acceptable level. The innovative Freescoo HVAC system was introduced and used to demonstrate the potential for integrating HVAC systems with façade elements. However, there is no tangible data available for the Freescoo system in terms of operational energy performance when it is integrated within the building façade, so instead, the results from the BERTIM project will be used as a reference to predict the building operational energy performance, especially after it has been equipped with the off-site prefabricated façade system.

\subsection{Operational Energy Performance Prediction}

The BERTIM project clearly indicates that by increasing the insulation level of the building significant savings are achieved in space heating energy due to lower losses through the building envelope. An experimental campaign over the BERTIM system is presented [32]. This campaign was conducted in the KUBIK by TECNALIA test facility [33]. The research aimed for full-scale realistic testing and this setup allowed for validation of constructional and energy performance issues, not only under ideal conditions but with real-life issues, such as junctions with other systems and thermal bridges. In this test, BERTIM proved its capacity to reduce heat transfer across the façade by a factor of 7, reaching an R-value of $5.07 \mathrm{~m}^{2} \mathrm{~K} / \mathrm{W}$. By itself, this experimental system proves the possibility of reaching NZEB performance levels with such systems. Figure 14 presents an overall picture of the experimental setup [34].

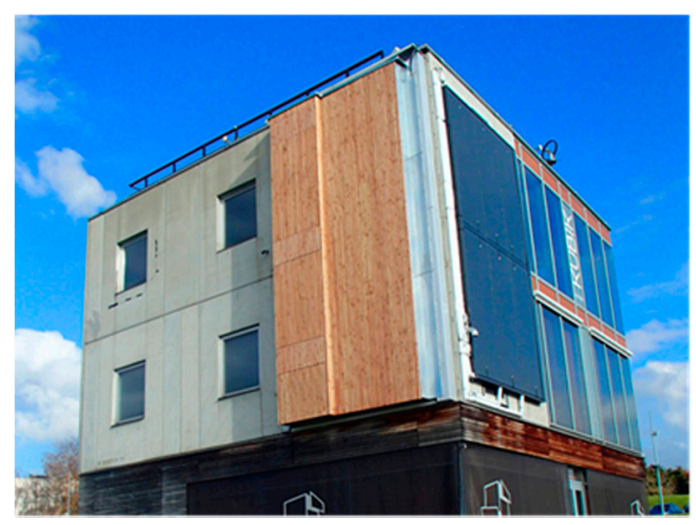

Figure 14. BERTIM system installed in a section of the west façade at the KUBIK by Tecnalia test facility.

Regarding the impact of the system to the energy levels of the whole building, energy assessments were conducted over an existing multi-rise building in Madrid. According to national energy rating tools, the integration of BERTIM allowed a whole-year heating demand reduction from $83 \mathrm{kWh} / \mathrm{m}^{2}$ y to $26.78 \mathrm{kWh} / \mathrm{m}^{2}$ y (Government of Spain. Herramienta Unificada Lider Calener (HULC)) [35]. This heating load reduction by a factor of 4 , jointly with similar reductions in cooling loads, allowed the building to progress from energy rating $E$ to energy rating $B$.

Even though the proposed integrated façade system is in the PoC stage, according to the aforementioned research and case studies, the results are compelling, which indicates that the proposed integrated façade system is applicable for adopting automated installation approaches and can potentially improve building lifecycle energy performance.

\subsection{Importance of Cross-Disciplinary Collaboration}

A highly flexible integrated façade system, along with an accompanying interior partition wall system and a suspended floor system, was proposed together with an innovative installation method that implements automation and robotic technology. To achieve such a comprehensive objective, it is essential to have extensive, cross-disciplinary teamwork between all stakeholders and the project team 
should involve the key stakeholders from an early stage of the project. However, such collaboration is often lacking in the low energy-efficiency building sector, and in fact, due to the fragmentation of the construction industry, cross-disciplinary collaboration has proven to be difficult, especially when involving new technologies or attempting to change existing working methods. Different from other industries, construction tasks have multiple steps, which involve a multitude of stakeholders. Each construction step is carried out by specific professionals and each stakeholder has specific interests. Construction tasks are often influenced by other factors such as on-site conditions, weather, the skill sets of the professionals, and the economic climate. As a result, the conventional construction industry often lacks efficient communication and common goals and is slow to accept new technologies. Therefore, promoting the proposed systems requires that the involved stakeholders work together closely and establish a common understanding of the goals and solutions. During the course of the ZERO-PLUS project and the construction robotics consultancy project, it is notable that cross-industry collaboration is extremely important when developing a new construction-related system or method and has huge implications for the success of the final implementation and market adoption.

\section{Conclusions and Recommendations}

To achieve an optimum energy-efficiency level in new-build or renovation projects proves to be a challenging task. The designers need to consider the entire construction phases, including the designing of the building structure and envelope, planning the construction process, end-of-life management, and to implement appropriate integration strategies. At the same time they should be assisted by decision support tools and an innovative construction method, and adopt cross-disciplinary collaboration. This research proposed an integrated façade system that is produced off-site and is well-insulated and equipped with the Freescoo HVAC system. Two scenarios were proposed to demonstrate the flexibility in design, efficiency in installation, cost-effectiveness, and improvements in energy requirements and building lifecycle management aspects for new builds as well as renovation projects. The first scenario was inspired by the ZERO-PLUS project, OB concepts and off-site prefabrication technologies to allow the proposed integrated façade system to be easily installed on-site using conventional construction tools. Meanwhile, the versatile interior partition wall and suspended floor system further complemented the overall performance of the system, which provided additional flexibility over the building lifecycle and made the system adaptable to future changes in terms of the occupants or building configuration. The second scenario was inspired by the CDPR developed in the Hephaestus project, which proposed a CDPR system specifically designed for handling and fastening the installation channel and for incorporating the optimum level of automation and human collaboration. Based on the outcomes of the Hephaestus project, it demonstrated the potential of implementing automation and robotic technologies for improving the overall performance of the building installation process. The proposed CDPR can improve the efficiency of the installation task, improve safety, and be more cost-effective when dealing with mass-scale renovation projects. In addition, facilitated by BERTIM outcomes, there is significant energy performance gain when implementing off-site prefabricated façade elements for the renovation project.

Even though there are limited tangible data to fully support the research outlooks. Nonetheless, the research has considerable potential outcomes that could inspire a more integrated, multidisciplinary, and holistic approach to achieving an optimum energy-efficient level in new-build or renovation projects. Despite the encouraging potential outcomes, there are still many obstacles and challenges that lay ahead. Based on the research findings, off-site prefabrication and automation in construction are not widely discussed in the context of energy-efficient buildings or other sustainability-related topics. The implication of the research is not only to look into how prefabrication and automated installation methods could influence productivity, costs, and energy requirements, but also to recommend strategies that could further develop the featured PoC concepts. The proposed system would not be effective unless the following aspects are taken into consideration when developing the proposed integrated façade system: considering the building as a system, not just a single-use permanent structure; 
completing the design and detailed process-oriented plans before the construction work begins; being aware of the safety hazards when introducing new working methods, and, in the context of this research, it is vital to consider what kind of safety implications the construction robotics may have in the installation task. The research team needs to understand each other's interests, concerns, and contributions, and from a managerial aspect, a cross-disciplinary approach is therefore essential. Lastly, further developing the proposed system requires financial and institutional support, such as support and incentives from the construction industry and policymakers, as well as research funding from both European and national funding institutions. Overall, the outcome of this research shall also be used as an initial milestone for researchers to build up a research consortium that tackles the aforementioned topics and further bridges the gaps between academia and the construction industry.

Author Contributions: Conceptualization development, W.P., T.B., P.F.; Case study analysis, W.P., K.I., R.G.M., O.M.J.; System development, W.P., T.B.; Writing, W.P., R.G.M. All authors have read and agreed to the published version of the manuscript.

Funding: This research was funded by ZERO-PLUS, from the European Union's Horizon 2020 Research and Innovation Programme under Grant Agreement No. 678407. The authors would like to thank to following research projects: BERTIM received funding from the European Union's Horizon 2020 Research and Innovation Programme under Grant Agreement No. 636984. HEPHAESTUS received funding from the European Union's Horizon 2020 Research and Innovation Programme under Grant Agreement No. 732513.

Conflicts of Interest: The authors declare no conflict of interest.

\section{References}

1. Dong, Y.H.; Jaillon, L.; Chu, P.; Poon, C.S. Comparing carbon emissions of precast and cast-in-situ construction methods-A case study of high-rise private building. Constr. Build. Mater. 2015, 99, 39-53. [CrossRef]

2. Ramesh, T.; Prakash, R.; Shukla, K.K. Life cycle energy analysis of buildings: An overview. Energy Build. 2010, 42, 1592-1600. [CrossRef]

3. Thormark, C. A low energy building in a life cycle-Its embodied energy, energy need for operation and recycling potential. Build. Environ. 2002, 37, 429-435. [CrossRef]

4. Guggemos, A.A.; Horvath, A. Decision-support tool for assessing the environmental effects of constructing commercial buildings. J. Arch. Eng. 2006, 12, 187-195. [CrossRef]

5. Dixit, M.K. Life cycle embodied energy analysis of residential buildings: A review of literature to investigate embodied energy parameters. Renew. Sustain. Energy Rev. 2017, 79, 390-413. [CrossRef]

6. Koezjakov, A.; Urge-Vorsatz, D.; Crijns-Graus, W.; Van, d.B.M. The relationship between operational energy demand and embodied energy in Dutch residential buildings. Energy Build. 2018, 165, 233-245. [CrossRef]

7. Cole, R.J.; Kernan, P.C. Life-cycle energy use in office buildings. Build. Environ. 1996, 31, 307-317. [CrossRef]

8. Seyam, S. Types of HVAC systems. HVAC Syst. 2018, 49-66. Available online: https://www.researchgate.net/ publication/328948936_Types_of_HVAC_Systems (accessed on 30 June 2020). [CrossRef]

9. Mao, C.; Shen, Q.; Shen, L.; Tang, L. Comparative study of greenhouse gas emissions between off-site prefabrication and conventional construction methods: Two case studies of residential projects. Energy Build. 2013, 66, 165-176. [CrossRef]

10. Aye, L.; Ngo, T.; Crawford, R.H.; Gammampila, R.; Mendis, P. Life cycle greenhouse gas emissions and energy analysis of prefabricated reusable building modules. Energy Build. 2012, 47, 159-168. [CrossRef]

11. Carli, R.; Dotoli, M.; Pellegrino, R.; Ranieri, L. A decision making technique to optimize a buildings' stock energy efficiency. IEEE Trans. Syst. Man Cybern. Syst. 2017, 47, 794-807. [CrossRef]

12. Bock, T.; Linner, T. Robotic Industrialization; Cambridge University Press: New York, NY, USA, 2015. [CrossRef]

13. Gibb, A. Off Site Fabrication-Prefabrication, Preassembly and Modularisation; Whittles Publishing: Caithness, UK, 1999.

14. Grosskopf, K.R.; Elliott, J.W.; Killingsworth, J.E. Offsite construction-US market trends in prefabrication, in challenges for technology innovation: An agenda for the future. In Proceedings of the International Conference on Sustainable Smart Manufacturing, Lisbon, Portugal, 20-22 October 2016. [CrossRef]

15. Pan, W.; Gibb, A.G.F.; Dainty, A.R.J. Leading UK housebuilders' utilization of offsite construction methods. Build. Res. Inf. 2008, 36, 56-67. [CrossRef] 
16. Graham, J.T.; Peter, E.D.L.; Gary, D.H. Using national input/output data for embodied energy analysis of individual residential buildings. Constr. Manag. Econ. 2001, 19, 49-61. [CrossRef]

17. Annex 50 Prefabricated Systems for Low Energy Renovation of Residential Buildings. Available online: https://www.buildup.eu/en/explore/links/iea-ecbcs-annex-50-prefabricated-systems-low-energyrenovation-residential-buildings (accessed on 30 June 2020).

18. Sousa, J. Application of prefabricated panels for the energy retrofit of Portuguese residential buildings facades: A case study. Arch. Civ. Eng. 2013, 59,337-357. [CrossRef]

19. Salem, O.; Zimmer, E. Application of lean manufacturing principles to construction. Lean Constr. J. 2005, 2, 51-54.

20. Sacks, R.; Koskela, L.; Dave, B.A.; Owen, R. Interaction of lean and building information modeling in construction. Constr. Eng. Manag. 2010, 136, 968-980. [CrossRef]

21. Bock, T.; Linner, T.; Eibisch, N. Vertical shipyard: Technology transfer for automated con-and deconstruction. In Proceedings of the 28th International Symposium on Automation and Robotics in Construction, Seoul, Korea, 29 June-2 July 2011. [CrossRef]

22. Kendall, S.; Teicher, J. Residential Open Building; E\&FN Spon: London, UK, 2010. [CrossRef]

23. Holt, R.; Barnes, C. Towards an integrated approach to "design for X": An agenda for decision-based DFX research. Res. Eng. Des. 2010, 21, 123-136. [CrossRef]

24. Boothroyd, G. Product design for manufacture and assembly. Comput. Aided Des. 1994, 26, 505-520. [CrossRef]

25. Leslie, C.; Nobuyasu, M. Construction Robots: The Search for New Building Technology in Japan; ASCE Publications: Reston, VA, USA, 1998.

26. Bock, T.; München, T.U.; Linner, T.; München, T.U. Advanced construction and building technology. In Robot-Oriented Design; Cambridge University Press: New York, NY, USA, 2015. [CrossRef]

27. BERTIM. Available online: http://www.bertim.eu/index.php?option=com_content\&view=featured\&Itemid= 111\&lang=en (accessed on 22 May 2020).

28. Hephaestus. Available online: https://www.hephaestus-project.eu/ (accessed on 21 May 2020).

29. ZERO-PLUS. Available online: http://www.zeroplus.org/ (accessed on 23 May 2020).

30. Beccali, M.; Finocchiaro, P.; Motta, M.; di Pietra, B. Monitoring and energy performance assessment of the compact DEC HVAC system "Freescoo Facade". In Proceedings of the EuroSun Conference, Lampedusa, Italy, 10-13 September 2018. [CrossRef]

31. Kendall, S. Open building: An approach to sustainable architecture. J. Urban Technol. 1999, 6, 1-16. [CrossRef]

32. Martinez, R.G.; Chemisana, D.; Arrien, A.U. Dynamic performance assessment of multidimensional heat transfer in buildings. J. Build. Eng. 2019, 26, 100893. [CrossRef]

33. Garay, R.; Chica, J.A.; Apraiz, I.; Campos, J.M.; Tellado, B.; Uriarte, A.; Sanchez, V. Energy efficiency achievements in 5 years through experimental research in KUBIK. Energy Procedia 2015, 78, 865-870. [CrossRef]

34. Garay, M.R.; Benito, A.J.; Arregi, G.B. Full scale experimental performance assessment of a prefabricated timber panel for the energy retrofitting of multi-rise buildings. Energy Procedia 2017, 122, 3-8. [CrossRef]

35. HULC. Available online: https://www.codigotecnico.org/index.php/menu-recursos/menu-aplicaciones/282herramienta-unificada-lider-calener.html (accessed on 6 May 2020).

(C) 2020 by the authors. Licensee MDPI, Basel, Switzerland. This article is an open access article distributed under the terms and conditions of the Creative Commons Attribution (CC BY) license (http://creativecommons.org/licenses/by/4.0/). 